\title{
Totaliproductive Maintenance (Tpm) Analysis Using the Overall Equipment Effectiveness (Oee) Method and Six Big Losses on an Injection Molding Machine
}

\section{Analisis Total productive Maintenance (Tpm) Menggunakan Metode Overall Equipment Efectiveness (Oee) Dan Six Big Losses Pada Mesin Moulding Injection}

\author{
Mokhamad Ridloi ${ }^{1)}$ Ribangun Bamban Jakaria $^{2)}$ \\ \{mohamadridloi92@gmail.com ${ }^{1)}$ ribangunbz@umsida.ac.id $\left.{ }^{2)}\right\}$
}

Program Studi Teknik Industri, Universitas Muhammadiyah Sidoarjo, Indonesia

\begin{abstract}
Abstrack. PT. XYZ is a manufacturing company that produces a variety of materials from plastics, this company can not be separated from problems related to the effectiveness of machinery / equipment. The problem that is experienced today is that there is a lot of damage to the injection moulding machine that has decreased speed as a result of the damage to the number of defect parts because the machine often experiences breakdown. Data collection is conducted with structured observations and interviews. To solve the problem that occurs, done a machine maintenance or maintenance by means of measurement using the method of Total Productive Maintenance which includes Overall Equipment Effectiveness and Six Big Losses. This study aims to determine the level of equipment total production process, to determine the factors causing the value of overall equipment Efectivenees (OEE) low and identify losses that occur with the standard value of ...

Keywords: Overall Equipment effectiveness, Six Big Losses, Total Productive Maintenance
\end{abstract}

\begin{abstract}
Abstrak. PT. XYZ merupakan perusahaan yang bergerak di bidang manufaktur yang memproduksi berbagai bahan material dari plastik, perusahaan ini tidak lepas dari masalah yang berkaitan dengan efektifitas mesin/peralatan. Permasalahan yang di alami saat ini adalah terjadi banyaknya kerusakan pada mesin injection moulding yang mengalami penurunan kecepatan di akibatkan dari rusaknya jumlah part defect di karenakan mesin sering mengalami breakdown. Pengumpulan data dilakukan dengan observasi dan wawancara terstruktur. Untuk mengatasi permasalahan yang terjadi, di lakukan sebuah perawatan mesin atau maintenance dengan cara pengukuran menggunakan metode Total Productive Maintenance yang meliputi Overall Equipment Effectiveness dan Six Big Losses. Penelitian ini bertujuan untuk mengetahui tingkat peralatan total proses produksi, untuk menentukan faktor penyebab nilai Overall Equipment Efectivenees (OEE) rendah dan mengidentifikasih kerugian/losses yang terjadi dengan nilai standart yang ditentukan perusahaan $85 \%$. Sehingga dapat mengetahui serta mengeliminasi kerugian besar bagi perusahaan. Hasil dari penelitian ini di harapkan dapat mengevaluasi kinerja mesin dan menjaga agar terus mendapat perawatan yang lebih baik.

Kata kunci: Overall Equipment effectiveness, Six Big Losses, Total Productive Maintenance
\end{abstract}

\section{I.PENDAHULUAN}

Sebuah mesin bekerja secara efektif apabila dapat melakukan proses produksi selama jangka waktu yang telah disediakan tanpa mengalami ganguan, bekerja sesuai,dengan waktu yang ditentukan, dan menghasilkan produk-produk,yang baik. PT.XYZ terjadi permasalahan kinerja peralalatan pada mesin injection moulding, seperti menurunya kecepatan produksi mesin, produk yang dihasilkan oleh mesin tersebut sebagian besar menjadi produk yang cacat dan harus di kerjakan ulang. Perusahaan tersebut mengoperasikan mesin moulding injection untuk mencetak barang yang terbuat dari bahan plastik, pada mesin ini sering mengalami downtime dan breakdown paling banyak menyebabkan kerugian pada mesin.

Salah satu metode pengukuran yang dapat digunakan adalah Overal Equipment effectiveness (OEE). Pada metode ini terdiri dari tiga faktor yang saling berhubungan yaitu Avaibility, 
Procedia of Engineering and Life Science Vol. 1. No. 2 Juni 2021

Seminar Nasional \& Call Paper Fakultas Sains dan Teknologi (SENASAINS 2nd)

Universitas Muhammadiyah Sidoarjo

Peformance, dan Quality. Metode ini merupakan bagian utama dari sebuah sistem pemeliharaan yaitu Total Productivee Maintenance (TPM). Fungsi pada metode OEE tersebut untuk mengukur apakah peralatan produksi yang dapat melakukan secara baik dan benar. Pada perhitungan yang terjadi untuk OEE ini digunakan sebagai alat indikator keberhasilan dalam metode TPM.

Banyaknya breakdown yang terjadi pada mesin injection moulding serta kurang maksimalnya jumlah produksi yang menyebabkan kurangnya nilai efektivitas total mesin secara keseluruhan. Oleh karena itu akan dilakukan sejumlah pengamatan dan analisis lebih jauh untuk mengetahui prioritas untuk mengevaluasi penerapan Total Productive Maintenance.

Tujuan yang ingin dicapai dari penelitian ini adalah melakukan analisis dalam penerapan Total Productive Maintenance di perusahaan tersebut. mengetahui nilai dari Overall Equipment Effectivenes pada mesin, yang menjadi dasar faktor availability, peformance, rate, of quality. Mengetahui sejumlah faktor-fakor yang menjadi penyebab turunnya efektivitas melalui pengukuran six bigg losses dan mengidentifikasi faktor-faktor yang paling dominan dari ke enam faktor six big losses, melakukan analisis terhadap faktor yang paling memberikan nilai kontribusi paling besar dan menggunakan diagram fishbone. Dan memberikan suatu rekomendasi untuk mengatasi permasalahan utama dari ke enam faktor six big losses dengan melakukan pendekatan terhadap Total Productive Maintenance.

\section{METODE PENELITIAN}

\section{A. Total Productive Maintenance}

Total productive maintenance menurut (Nursubiyantoro,2016) agar tidak terfokus pada cara mengoptimalkan nilai produktivitas dari sebuah peralatan atau material pendukung suatu kinerja, tetapi juga memperhatikan bagaimana cara meningkatkan produktivitas dari pekerja atau operator yang nantinya akan memegang kendali pada peralatan dan material tersebut.

B. Overall Equipment Effectiveness

Overall Equipment Effectiveness (OEE) merupakan ukuran menyeluruh yang mengidentifikasikan tingkat produktivitas mesin/peralatan dari kinerja secara teori. Pengukuran ini sangat penting untuk mengetahui area mana yang perlu ditingkatkan produktivitasnya ataupun efisiensi mesin/peralatan dan juga dapat menunjukkan proses produksinya.

Tabel 1 nilai standart ideal perhitungan OEE

\begin{tabular}{ll}
\hline Deskripsi & Nilai \\
\hline Avaibility & $>90 \%$ \\
Performance & $>95 \%$ \\
Quality & $>99 \%$ \\
OEE & $>85 \%$ \\
\hline
\end{tabular}

Tabel 2. Hasil rekapitulasi waktu kerusakan pada mesin injection moulding

\begin{tabular}{|c|c|c|c|c|}
\hline \multirow{2}{*}{ Tanggil } & \multicolumn{2}{|c|}{ Wektu Jeda Kerusaakan } & \multirow{2}{*}{ Jenis kecacatan } & \multirow{2}{*}{$\begin{array}{c}\text { Durasi } \\
\text { Per Menit }\end{array}$} \\
\hline & Mzlai & Salesai & & \\
\hline Jan-2-2020 & 4:05 & $10: 17$ & Oli Tangki Mesin Retak & 372 \\
\hline Jan-9-2020 & $3: 55$ & $8: 45$ & Power Pln Off & 290 \\
\hline Jan-16-2020 & $6: 10$ & $7: 15$ & Motor Pompa Oli & 65 \\
\hline Januari-20-2020 & $10: 15$ & 12:04 & Emergency Stop & 139 \\
\hline Januari -25-2020 & $7: 55$ & $9: 40$ & Pompa Udara Dari Sistem Hidrolic & 105 \\
\hline Januari -31-2020 & 11.26 & 20.27 & Temp Barell Low & 531 \\
\hline Februari-6-2020 & $5: 35$ & $22: 45$ & Moulding High Press & 1009 \\
\hline Februari -13-2020 & $16: 55$ & $23: 10$ & Temperatur Oli High & 375 \\
\hline Februari -22-2020 & $4: 12$ & $11: 30$ & Extruder & 678 \\
\hline Maret-5-2020 & $15: 43$ & $18: 53$ & Brangkas Dari Controller & 190 \\
\hline
\end{tabular}


Procedia of Engineering and Life Science Vol. 1. No. 2 Juni 2021

Seminar Nasional \& Call Paper Fakultas Sains dan Teknologi (SENASAINS 2 ${ }^{\text {nd }}$ )

Universitas Muhammadiyah Sidoarjo

\begin{tabular}{ccccc}
\hline & & & & \\
\hline Maret -14-2020 & $13: 32$ & $17: 21$ & Power Pln Off & 235 \\
Maret-18-2020 & $0: 00$ & $9: 04$ & Suhu Panas Injeksi & 548 \\
Maret-25-2020 & $8: 12$ & $12: 50$ & Pemanas & 278 \\
Maret-31-2020 & $10: 35$ & $22: 25$ & Nozzel & 710 \\
April-4-2020 & $10: 00$ & $15: 34$ & Power Pln Off & 334 \\
April-14-2020 & $0: 00$ & $11: 23$ & Sistem Keamanan Hidrolic & 683 \\
April-22-2020 & $5: 22$ & $10: 33$ & Sistem Pengaman Mekanis & 311 \\
April-27-2020 & $16: 00$ & $18: 10$ & Pembersihan Cetakan & 130 \\
\hline
\end{tabular}

Tabel 2. Hasil rekapitulasi waktu kerusakan pada mesin injection moulding lanjutan,,,)))

$\begin{array}{ccccc}\text { Mei-5-2020 } & 10.09 & 19.00 & \text { Temp Barell Low } & 531 \\ \text { Mei-11-2020 } & 16: 55 & 23: 10 & \text { Temperatur Oli High } & 375 \\ \text { Mei-14-2020 } & 5: 06 & 16: 58 & \text { Moulding High Press } & 712 \\ \text { Mei-19-2020 } & 12: 02 & 19: 00 & \text { Secrew Tidak Mau Charging } & 238 \\ \text { Mei-28-2020 } & 4: 12 & 11: 42 & \text { Extruder } & 450 \\ \text { Juni-3-2020 } & 12: 32 & 14: 20 & \text { Pergantian Matras Frame } & 108\end{array}$

III. HASIL DAN PEMBAHASAN

TABEL 3 PERHITUNGAN AVAILABILITY MESIN INJECTION MOULDING

\begin{tabular}{ccccc}
\hline Bulan & Loadiang Tima & Total Doewntime & Operationg Time & Available \%) \\
\hline Januari & 744 & 25,03 & 718,97 & $96,64 \%$ \\
Februari & 644 & 84,36 & 609,64 & $94,66 \%$ \\
Maret & 744 & 32,68 & 711,32 & $95,61 \%$ \\
April & 720 & 24,3 & 695,7 & $96,63 \%$ \\
Mei & 704 & 78,43 & 665,57 & $94,54 \%$ \\
Juni & 720 & 37,8 & 682,2 & $94,75 \%$ \\
Jumlah & 4276 & 282,6 & 4083,4 & $95,47 \%$ \\
\hline
\end{tabular}

$$
\% \text { Performance }=\frac{\text { Total Produksi X Waktu Siklus Ideal Per Unit }}{\text { Operating Time }} \times 100 \%
$$

TABEL 4 PERHITUNGAN PERFORMANCE RATE MESIN INJECTION MOULDING

\begin{tabular}{lcccc}
\hline Periiode & $\begin{array}{c}\text { Total } \\
\text { Prossesd product } \\
\text { (Unit) }\end{array}$ & $\begin{array}{c}\text { Idil Cyccle Time } \\
\text { (Jam) }\end{array}$ & $\begin{array}{c}\text { Operationg Time } \\
(\mathrm{Jam})\end{array}$ & $\begin{array}{c}\text { Performannce } \\
\text { Effeciency(\%) }\end{array}$ \\
Januari & 25744 & 0,016 & 718,97 & $57,29 \%$ \\
Februari & 36830 & 0,016 & 609,64 & $96,66 \%$ \\
Maret & 40675 & 0,016 & 711,32 & $91,49 \%$ \\
April & 41575 & 0,016 & 695,7 & $95,62 \%$ \\
Mei & 40935 & 0,016 & 665,57 & $98,41 \%$ \\
Juni & 41371 & 0,016 & 682,2 & $97,02 \%$ \\
Jumlah & 227130 & 0,096 & 4083,4 & $89,41 \%$ \\
\hline
\end{tabular}

$$
\frac{\text { total product }- \text { defect }}{\text { total product }} \times 100
$$

TABEL 5 PERHITUNGAN QUEALITY RETA MESIN INJECTIION MOULDING

Bulan Total Presentase $\quad$ Total Defecct Quality Product (\%)


Procedia of Engineering and Life Science Vol. 1. No. 2 Juni 2021

Seminar Nasional \& Call Paper Fakultas Sains dan Teknologi (SENASAINS 2 ${ }^{\text {nd }}$ )

Universitas Muhammadiyah Sidoarjo

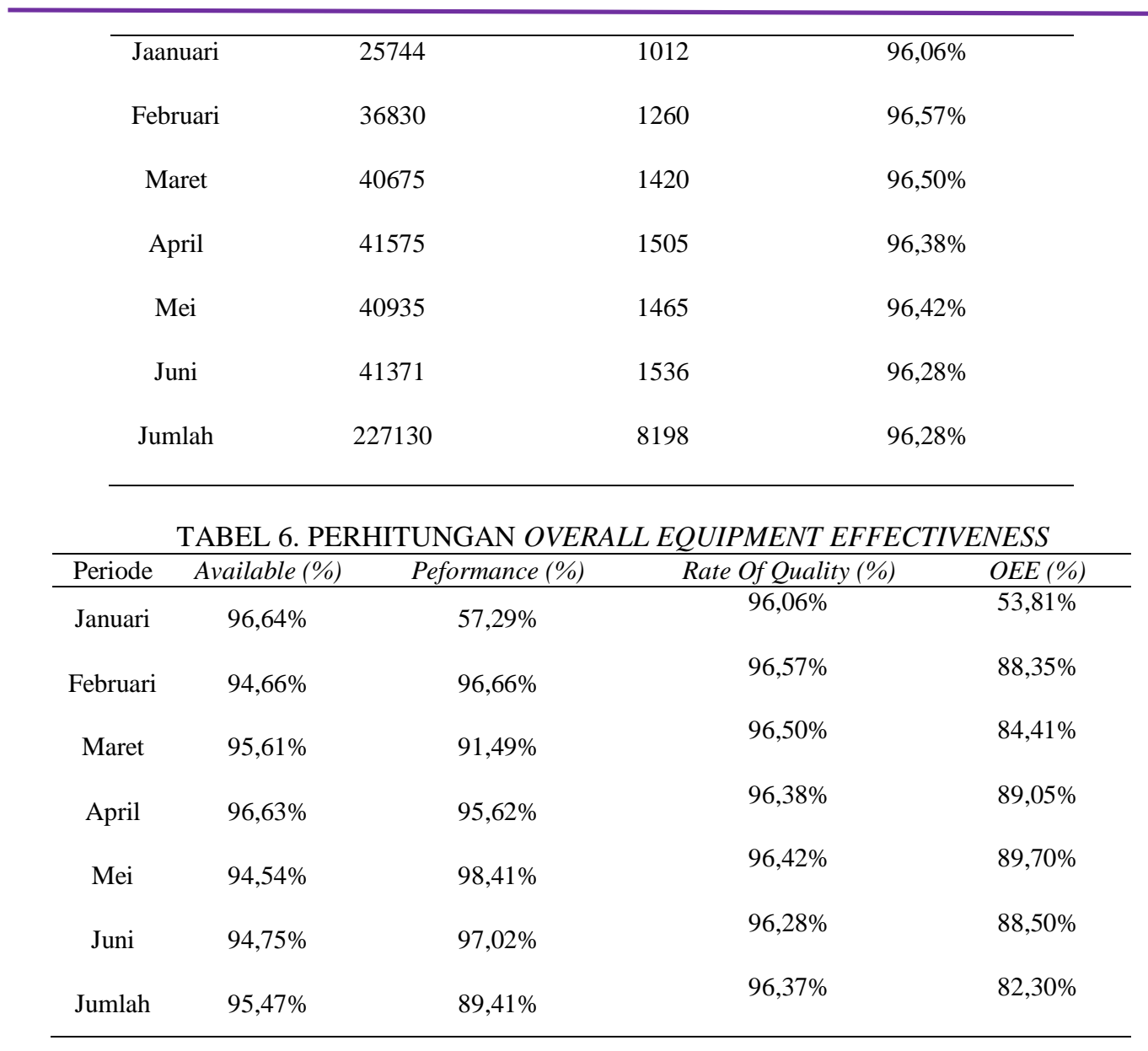

\section{A. PERHITUNGAN OVERALL EQUIPMENT EFFECTIVENESS PADA SIX BIG LOSSES}

Breakdown loss

Breakdown losses dapat dikategorikan sebagai Downtime losses karadinya kerusakan pada mesin dan peralatan hingga perawatan yang sebagian tidak dapat terjadwal yang mengakibatkan banyaknya waktu proses produksi terbuang.

$$
\frac{\text { total breakdown time }}{\text { loading time }} \times 100 \%
$$

TABEL 7 Total Breakdown Time Mesin Injection

\begin{tabular}{cccc}
\hline Periode & Poweer Cute Off-Jam & Machinne Breaak Jam & Total \\
\hline Januari & 4,833 & 20,2 & 25,033 \\
Februari & 0 & 34,366 & 34,366 \\
Maret & 3,916 & 28,766 & 32,682 \\
April & 5,566 & 18,733 & 24,299 \\
Mei & 0 & 38,433 & 38,433 \\
Juni & 6,716 & 31,084 & 37,8 \\
\hline
\end{tabular}

Breakdown loss $\frac{20,2}{744} \times 100 \%=2,715 \%$

TABEL 8 Equipmeent Failuure Losses Mesin Injection 
Procedia of Engineering and Life Science Vol. 1. No. 2 Juni 2021

Seminar Nasional \& Call Paper Fakultas Sains dan Teknologi (SENASAINS 2nd)

Universitas Muhammadiyah Sidoarjo

\begin{tabular}{cccc}
\hline Periode & Total Breaakdown & $\begin{array}{c}\text { Loaeding Time } \\
(\mathrm{Jam})\end{array}$ & Breaakdown $(\%)$ \\
\hline Jaanuari & 20,2 & 744 & $2,715 \%$ \\
Februari & 34,366 & 644 & $5,336 \%$ \\
Maret & 28,766 & 744 & 3,866 \\
April & 18,733 & 720 & $2,602 \%$ \\
Mei & 38,433 & 744 & $5,166 \%$ \\
Juni & 31,084 & 720 & $4,317 \%$ \\
Total & 179,081 & 4316 & $24,003 \%$ \\
\hline
\end{tabular}

$\frac{\text { Total set up and adjustment time }}{\text { Loading time }} \times 100 \%$

TABEL 9 Setip And Adjustment Mesin Injection

\begin{tabular}{ccccccc}
\hline Bulan & $\begin{array}{c}\text { Shcedule } \\
\text { Shutdown }(\mathrm{Jam})\end{array}$ & $\begin{array}{c}\text { And Adjustment } \\
\text { Presentase } \\
\text { Sparepart }\end{array}$ & $\begin{array}{c}\text { Warm Up } \\
\text { Time }\end{array}$ & $\begin{array}{c}\text { Total } \\
\text { (Jam) }\end{array}$ & $\begin{array}{c}\text { Loading Time } \\
\text { Setup Loss } \\
(\%)\end{array}$ \\
\hline Jaanuari & 0 & 0 & 0 & 0 & 744 & $0 \%$ \\
Februeari & 0 & 0 & 0 & 0 & 644 & $0 \%$ \\
Mareet & 0 & 0 & 0 & 0 & 744 & $0 \%$ \\
April & 0 & 0 & 0 & 0 & 720 & $0 \%$ \\
Mei & 0 & 0 & 0 & 0 & 744 & $0 \%$ \\
Juni & 0 & 1,733 & 0 & 0 & 720 & $0,240 \%$ \\
Total & 0 & 1,733 & 0 & 0 & 4316 & $0,240 \%$ \\
\hline
\end{tabular}

$$
\frac{\text { Non Productive Time }}{\text { Loading Time }} \times 100 \%
$$

TABEL 10 Presentase Idiling And Minoor Sttoppages Mesin Injection

\begin{tabular}{cccc}
\hline Bulan & $\begin{array}{c}\text { Machine Injection } \\
\text { Cleaning (Jam) }\end{array}$ & Loading Time (Jam) & $\begin{array}{c}\text { Idiling And Minor } \\
\text { Stopages (\%) }\end{array}$ \\
\hline Januari & 0 & 744 & 0 \\
Febuari & 0 & 644 & 0 \\
Maret & 0 & 744 & 0 \\
April & 2,166 & 720 & 0,301 \\
Mei & 0 & 744 & 0 \\
Juni & 0 & 720 & 0 \\
Total & 2,166 & 4316 & 0,301 \\
\hline
\end{tabular}

$\frac{\text { Operational Time }-(\text { idle cycle time } x \text { total product processed }}{\text { Loading Time }} \times 100 \%$

TABEL 11 Presentase Reducced Speed Loss Mesin Injection

\begin{tabular}{ccccccc}
\hline Bulan & $\begin{array}{c}\text { OperationgTime } \\
\text { (Jam) }\end{array}$ & $\begin{array}{c}\text { Ideial } \\
\text { Cyccle Time }\end{array}$ & $\begin{array}{c}\text { Total Product } \\
\text { Prossesd }\end{array}$ & $\begin{array}{c}\text { Loading } \\
\text { Time }\end{array}$ & $\begin{array}{c}\text { Reduced } \\
\text { Speed Loss } \\
\text { Time }\end{array}$ & $\begin{array}{c}\text { Reduced } \\
\text { Speed Loss }\end{array}$ \\
\hline Januari & 718,97 & 0,016 & 25744 & 744 & 307,066 & $41 \%$ \\
\hline
\end{tabular}


Procedia of Engineering and Life Science Vol. 1. No. 2 Juni 2021

Seminar Nasional \& Call Paper Fakultas Sains dan Teknologi (SENASAINS 2 ${ }^{\text {nd }}$ )

Universitas Muhammadiyah Sidoarjo

\begin{tabular}{ccccccc}
\hline Februari & 609,64 & 0,016 & 36830 & 644 & 20,36 & $3,16 \%$ \\
Maret & 711,32 & 0,016 & 40675 & 744 & 60,52 & $8,13 \%$ \\
April & 695,7 & 0,016 & 41575 & 720 & 30,5 & $4,23 \%$ \\
Mei & 665,57 & 0,016 & 40935 & 744 & 10,61 & $1,42 \%$ \\
Juni & 682,2 & 0,016 & 41371 & 720 & 20,264 & $2,81 \%$ \\
Total & 4083,4 & 0,096 & 227130 & 4316 & 438,71 & $61,02 \%$ \\
\hline
\end{tabular}

idle cycle time $x$ ReworkRework Loading Time

TABEL 11 PRESENTASE REWORK LOSS MESIN INJECTION

\begin{tabular}{cccccc}
\hline Bulan & $\begin{array}{c}\text { Loaiding Time } \\
(\mathrm{Jam})\end{array}$ & $\begin{array}{c}\text { Idle Cyclle Time } \\
(\mathrm{Jam})\end{array}$ & Reework & $\begin{array}{c}\text { Reework Time } \\
(\mathrm{Jam})\end{array}$ & $\begin{array}{c}\text { Reework Loss } \\
\%\end{array}$ \\
\hline Jaanuari & 744 & 0,016 & 1012 & 0,021 & $2,17 \%$ \\
Febuari & 644 & 0,016 & 1260 & 0,031 & $3,13 \%$ \\
Maret & 744 & 0,016 & 1420 & 0,305 & $3,05 \%$ \\
April & 720 & 0,016 & 1505 & 0,033 & $3,34 \%$ \\
Mei & 744 & 0,016 & 1465 & 0,031 & $3,15 \%$ \\
Juni & 720 & 0,016 & 1536 & 0,034 & $3,41 \%$ \\
Total & 4316 & 0,096 & 8198 & 0,455 & $18,25 \%$ \\
\hline
\end{tabular}

$\frac{\text { Idle Cycle Time } x \text { Scrap }}{\text { Loading Time }} \times 100 \%$

TABEL 12 PRESENTASE YEILD/ SRAP LOSSES MESIN INJECTION

\begin{tabular}{cccccc}
\hline Bulan & $\begin{array}{c}\text { Loading Time } \\
(\text { Jam) }\end{array}$ & $\begin{array}{c}\text { Idle Cycle Time } \\
(\text { Jam) }\end{array}$ & Scrap & Scraap Time & Scraap Loss \% \\
\hline Jaanuari & 744 & 0,016 & 0, & 0, & $0 \%$ \\
Febuari & 644 & 0,016 & 0, & 0, & $0 \%$ \\
Marett & 744 & 0,016 & 0, & 0, & $0 \%$ \\
Apr & 720 & 0,016 & 0, & 0, & $0 \%$ \\
Mey & 744 & 0,016 & 0, & 0, & $0 \%$ \\
Junii & 720 & 0,016 & 0, & 0, & $0 \%$ \\
Total & 4316 & 0,096 & 0, & 0, & $0 \%$ \\
\hline
\end{tabular}

B. ANALISIS SIX BIG LOSSES

Setelah melakukan perhitungan enam losses yang ada maka didapatkanlah hasil losses, kemudian didapatkan faktor yang menjadi hal utama yang diakibatkan kurangnya kinerja mesin.

TABEL 13 Presentasse six biig,Loss Mesin,Injection

\begin{tabular}{cccc}
\hline No & Six Biig Losses & Total Time Loss (Jam) & Presentase \% \\
\hline 1 & Breaakdown Losss & 179,081 & $24,003 \%$ \\
2 & Set Up Adjusment & 0 & $0 \%$ \\
3 & Idiling Minor Stoppages & 2,166 & $0,30 \% 1$ \\
4 & Reduced Speed Losses & 438,71 & $61,02 \%$ \\
\hline
\end{tabular}


Procedia of Engineering and Life Science Vol. 1. No. 2 Juni 2021

Seminar Nasional \& Call Paper Fakultas Sains dan Teknologi (SENASAINS 2nd)

Universitas Muhammadiyah Sidoarjo

\begin{tabular}{cccc}
\hline 5 & & & \\
6 & Rework Loss & 0,455 & $18,25 \%$ \\
& Scrap/Yeild & 0 & $0 \%$ \\
& Total & 620,412 & $103,574 \%$ \\
\hline
\end{tabular}

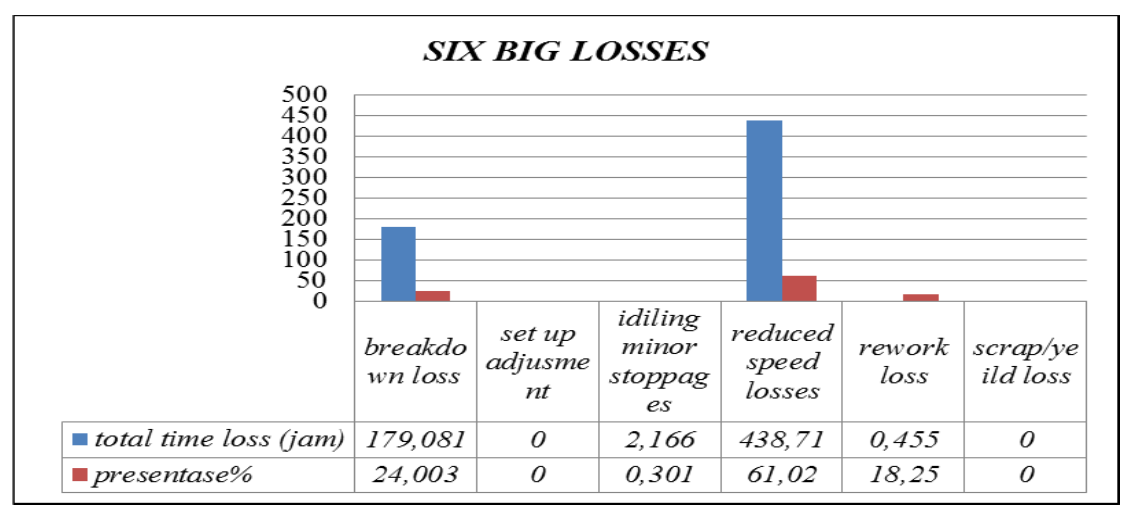

Gambar 1 Grafik histogram presentase six big losses

TABEL 14 PENGURUTAN PRESENTASE FAKTOR BIG LOSSES MESIN INJECTION

\begin{tabular}{ccccc}
\hline No & Six Big Losses & Total Time Loss (Jam) & Presentase & $\begin{array}{c}\text { Presentase } \\
\text { Kumulatif }\end{array}$ \\
\hline 1 & Reduced Speed Losses & 438,71 & $61,02 \%$ & $59 \%$ \\
2 & Breakdown Loss & 179,081 & $24,003 \%$ & $23 \%$ \\
3 & Idiling Minor & 2,166 & $0,301 \%$ & $0 \%$ \\
4 & Stoppages & 0,455 & $18,25 \%$ & $18 \%$ \\
5 & Rework loss & 0, & $0, \%$ & $0 \%$ \\
6 & Set-up and adjustment & 0, & $0, \%$ & $0 \%$ \\
& Scraap/Yeild & 620,412 & 104,615 & $100 \%$ \\
\hline
\end{tabular}

\section{ANALISIS DIAGRAM SEBAB AKIBAT/FISHBONE}

Di ketahui bahwa penyebab dari rendahnya nilai oveall equipment effectivenees adalah reduced speed losses dan breakdown loss, kemudian ara mengetahui jenis akar penyebabnya dengan menggunakan diagram fishbone.

\section{REDUCED SPEED LOSSES}

Pada reduced speed losses merupakan suatu kerugian yang terjadi akibat penurunan kecepatan operasi mesin dari kecepatan normal yang dimilkinya. Hal ini akan berdampak pada kurangnya jumlah produk yang dihasilkan. 
Procedia of Engineering and Life Science Vol. 1. No. 2 Juni 2021

Seminar Nasional \& Call Paper Fakultas Sains dan Teknologi (SENASAINS 2 ${ }^{\text {nd }}$ )

Universitas Muhammadiyah Sidoarjo

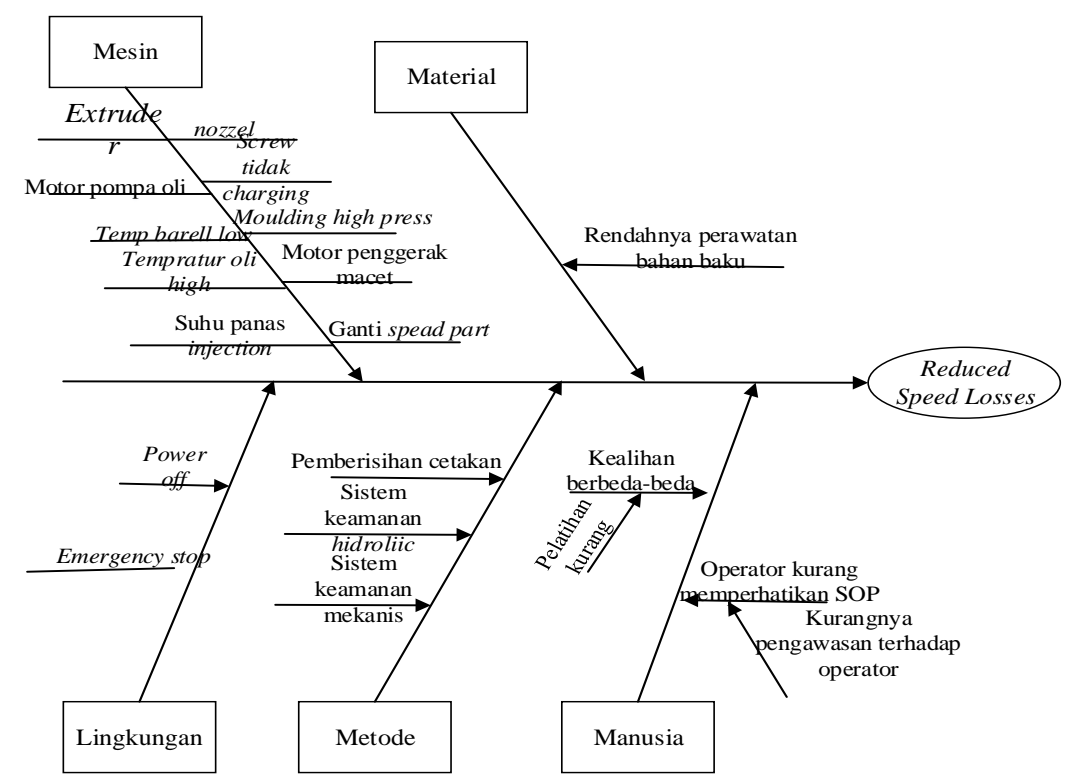

Gambar 2 Diagram sebab akibat (fishbone) reduced speed losses

\section{KESIMPULAN}

Setelah dilakukan pembahasan-pembahasan sebelumnya pada penelitihan ini, dapat diambil suatu kesimpulan sebagai berikut :

a. Pencapaian hasil pengukuran nilai OEE pada mesin injection moulding rata-rata selama bulan januari sampai juni sebesar $82,30 \%$, namun nilai tersebut masih dibawah nilai standart yang diharapkan yaiitu sebesar $85 \%$.

b. Reduced speed losses mendapatkan presentase sebanyak 59\%, ini terjadi dikarenakan mesin tidak bekerja secara optimal dan berakibat pada penurunan operasi pada peralatan tersebut.

c. breakdown loss mendapatkan presentase sebanyak 235, pada faktor kerusakan jenis ini sebuah mesin atau peralatan yang tiba-tiba mengalami kerusakan yang tidak diinginkan tentu saja menjadi sebuah kerugian

d. Set-up and adjustment mendapatkan nilai $0,24 \%$, pada hal ini tidak mengalami kerusakan yang di akibatkan adanya waktu yang terbuang pada mesin Injection Moulding.

e. Idiling and minor stoppsges mendapatkan nilai tertinggi yaitu pada bulan april dengan total nilai 2,166 jam,.

f. Rework loss mendapatakan presentase nilai total rework loss sebesar 18,25\%. Hal ini terjadi karena suhu panas pada mesin injection moullding menurun,

g. Yield/scrap losses mendapatkan presentase nilai dengan total idle cycle time 0,9096 jam, analisis diagram sebab akibat (fishbone diagram)

\section{REFERENSI}

[1] Andita rahayu, (2014). EVALUASI EFEKTIVITAS MESIN KLIN DENGAN PENERAPAN TOTAL PRODUCTIVE MAINTENANCE PADA PABRIK PT SEMEN PADANG. Vol.13 No.1 April 2014

[2] Anwar, Syukriah, Muslem (2016). ANALISIS OVERALL EQUIPMENT EFFECTIVENESS (OEE) DALAM MEMINILIMALISIR SIX BIG LOSSES PADA MESIN PRODUKSI DI UD. HIDUP BARU. Industrial Engineering Journal Vol.5 No.2 (2016) 52-57 Deny Andesta M. Nur Hasyim, Said Salim Dahda.(2018). ANALISA NILAI OVERALL EQUIPMENT EFFECTIVENESS PADA MIXING MACHINE TYPE B.

[3] Ashish M Gohil, Dhaval B Shah, Ranteshwar Singh* (2012). TOTAL PRODUCTIVE MAINTENANCE (TPM) IMPLEMENTASI DI SEBUAH MESIN. Procedia Teknik 51 (2013) 592-599. 
Procedia of Engineering and Life Science Vol. 1. No. 2 Juni 2021

Seminar Nasional \& Call Paper Fakultas Sains dan Teknologi (SENASAINS 2nd)

Universitas Muhammadiyah Sidoarjo

[4] Deny Andesta M. Nur Hasyim, Said Salim Dahda.(2018). ANALISA NILAI OVERALL EQUIPMENT EFFECTIVENESS PADA MIXING MACHINE TYPE B.

[5] Eko Nursubiyantoro, Mohamad Isnaini Rozaq, dan Puryani(2016). IMPLEMENTASI TOTAL PRODUCTVE MAINTENANCE (TPM) DALAM PENERAPAN OVERALL EQUIPMENT EFFECTIVENESS (OEE). Jurnal OPSI Vol. 9 No.1 Juni 2016.

[6] Hermanto. (2016) PENGUKURAN NILAI OVERALL EQUIPMENT EFFECTIVENESS PADA DIVISI PAINTING DI PT.AIM. jurnal metris, 17 (2016): 97-106

[7] Hery Suliantoro, Heru Prastawa, Novie Susanto*), dkk. (2017). PENERAPAN METODE OVERALL EQUIPMENT EFFECTIVENESS (OEE) DAN FAULT TREE ANALYSIS (FTA) UNTUK MENGUKUR EFEKTIFITAS MESIN RENG. Jurnal Teknik Industri Vol. 12, No.2, Mei 2017

[8] Irwan Yulianto, Rispianda, Hendro Prassetiyo. (2014). RANCANGAN DESAIN MOLD PRODUK KNOB REGULATOR KOMPOR GAS PADA PROSES INJECTION MOLDING*. No.03 Vol.02, Juli 2014

[9[ Pratikno, Rahmad, Slamet Wahyudi. (2012). PENERAPAN OVERALL EQUIPMENT EFFECTIVENESS (OEE) DALAM IMPLEMENTASI TOTAL PRODUCTIVE MAINTENANCE (TPM). Vol.3, No.3 tahun $2012:$ 431-437 